\title{
Optimal Decisions for a Dual Channel Supply Chain
}

\author{
Xuenan Zhou and Xiaoshen $\mathrm{Li}^{*}$ \\ Mathematics and Statistics, Henan University of Science and Technology, Luoyang 471023, China \\ ${ }^{*}$ Corresponding author
}

Keywords: Supply chain, Dual channel, Markup, Lead time, Service level.

\begin{abstract}
This paper considers a two-stage dual-channel supply chain consisting of a manufacturer and a retailer. The manufacturer produce both standard and customized products. The standard products sell through the retailer, and the customized products sell through the Internet. Due to the different ways of sales, the efforts of the two channels are shown as service level and lead time respectively. Both demands for the two types of products are linearly related to sales price, service level and lead time. The objective is to make the optimal decisions, including markup on the products, service level of the retailer, lead time for the customized products, production lots of the manufacturer, and order times of the retailer, so as to maximize the profit of the supply chain system. For the problem, the nonlinear constrained programming model is established, the solution is discussed, Matlab programs for solving the problem are developed. Through numerical experiments, useful conclusions are drawn for both supply chain managers and researchers.
\end{abstract}

\section{Introduction}

In recent years, with the rapid development of e-commerce and information technology, consumer behavior has changed and manufacturers' sales strategies have also changed. In addition to traditional sales channels, manufacturers have begun to sell their products through online channels or the coexistence of online channels and traditional channels. Many companies such as Dell, IBM, Nike, HP, Apple, Estee Lauder and Pioneer Electronics have adopted a dual-channel sales strategy [1-6]. With a single channel compared with daoism, the management of dual-channel supply chain is much more complicated, which needs to redesign the supply chain structure and determine its production inventory strategy.

The hot issues in the field of supply chain management include the impact of pricing, effort level and production inventory on supply chain decision-making. Chiang et al. [2] and Tsay, Agrawal[3] studied the dual-channel supply chain problem with pricing and channel structure as decision variables and found that the use of online channels improved the channel efficiency. Hua et al. [4] studied the pricing problem of dual-channel supply chain considering lead time under centralized and decentralized strategies, and found that lead time affects pricing strategy and supply chain profit. Xia and Rajagopalan [7] studied the standardization and customization of products of the two competing companies by integrating product categories, lead time and price, and found that increasing product categories or reducing delivery time can increase market share and profit. Dan et al. [8] studied the strategic role of retail services in the dual-channel supply chain, indicating that retail services directly affect the overall profits of the system and the pricing strategies of manufacturers and sellers. Xiao et al. [9] used the Stackelberg pricing model to study the type and structure of dual-channel products and found that the introduction of online channels for customized products makes the wholesale price and retail price of standard products increase when the booking price of retail channels is low enough. $\mathrm{Li}$ et al. [10] studied customers' sensitivity to channel acceptance and product differences, and found that manufacturers improved the profits of manufacturers and sellers by selling customized products online. Batarfi, Jaber et al. [11] studied the two-level dual-channel supply chain problem consisting of one manufacturer and one seller. The manufacturer sells standard products through traditional channels, namely the seller, and sells customized products through direct online channels. They built a maximum model of the problem under linear demand conditions and compared it with two single-channel cases through numerical experiments. 
This paper is based on the research of Batarfi, Jaber et al., but considers the impact of sales efforts on the supply chain, including the order lead time of customized products and the service level of the seller. Some redundancy was removed, such as the degree of differentiation of the custom product, which was considered but treated as constant. In this way, there is no benefit other than increasing the complexity of the problem. In this paper, a more feasible solution method is given and more practical results are obtained.

\section{Model Framework}

\section{Assumptions}

(1)In the two-level dual-channel supply chain composed of a manufacturer and a seller, the manufacturer produces both standard products and customized products. Standard products are sold by sellers through traditional sales channels. Customized products are sold through (Internet) direct sales channels.

(2)Standard products are formed by adding basic features to core products, while customized products are produced by adding corresponding features to core products according to customer preferences. Different features added to core products produce different customized products that can be expressed as sets $G_{M}=\left\{G_{i}, i=1,2, \ldots, M\right\}$.

(3)Standard products are consigned, and the inventory is managed by the seller, who only pays the manufacturer for the products sold at the wholesale price. The quantity produced by the manufacturer per cycle is $q_{t}$, the sales cycle is the same as the production cycle, and the manufacturer delivers the same quantity to the seller each time, the number of deliveries per production cycle by the manufacturer is $n_{t}$, the production cycle of standard products is $q_{t} / D_{t}=n_{t} q / D_{t}$.

(4)The inventory of the core products used in the customized products is managed by the manufacturer. The quantity of core products produced by the manufacturer for each customized product is $q_{e}$, and the cycle of the customized products is $q_{e} / D_{e}$.

(5)No shortage is allowed in the sales process, that is, the productivity $P_{t}$ and $P_{e}$ of standard products and customized products are higher than the demand rate $D_{t}$ and $D_{e}$.

(6)During the sales process, both the manufacturer and the seller adopt the same mark-up rate $k$, $0 \leq k \leq k_{0}$. Where $k_{0}$ is the price increase upper limit stipulated by the price management regulations or regulations.

(7)Traditional sales channels and network direct sales channels need to make corresponding efforts in order to increase the demand rate, but due to the different sales methods of the two channels, the efforts made are also different. The efforts of the seller are to optimize the service level $s$, while the efforts of the manufacturer are to optimize the order lead time $l$. The service cost of the seller per unit time is $C_{s}(s)=a s^{2} / 2,0 \leq s \leq 1$; The processing and delivery cost of customized products per unit is $C_{l}(l)=c_{L}+b(L-l)^{2} / 2,0<L_{1} \leq l \leq L_{2}<L$. Where $s=0$ represents no service, $s=1$ represents the highest level of service, and $L_{1}$ and $L_{2}$ are the minimum and maximum lead times (delivery delays) respectively.

\section{Demand Rate Function}

Assuming that the demand for standard and customized products is linearly related to the sales price, service level and order lead time, the demand rate function of standard and customized products is as follows:

$$
D_{t}=\alpha_{t}-\beta_{t} c_{t}(1+k)^{2}+\sum_{i=1}^{M} \mu_{i} \gamma_{t i} c_{e i}(1+k)+\delta_{t} l+\tau_{t} s
$$




$$
D_{e}=\alpha_{e}-\sum_{i=1}^{M} \mu_{i} \beta_{e i} c_{e i}(1+k)+\gamma_{e} c_{t}(1+k)^{2}-\delta_{e} l-\tau_{e} s .
$$

Among them, parameters $\alpha_{t}$ and $\alpha_{e}$ are the market shares of standard products and customized products in the potential market demand respectively. $\beta_{t}$ and $\beta_{e i}$ are the sensitivity coefficients of the demand for standard product and customized product $i$ to the sales price. $\gamma_{t i}$ and $\gamma_{e}$ are the cross-sensitivity coefficients of the demand for standard product and customized product $i$ to the sales price respectively, they reflect the degree of substitutability of products sold through the two channels. $\delta_{t}$ and $\delta_{e}$ respectively represent the cross sensitivity coefficient and sensitivity coefficient of the demand for standard product and customized product $i$ to the lead time of ordering. $\tau_{t}$ and $\tau_{e}$ respectively represent the sensitivity coefficient and cross sensitivity coefficient of the demand for standard product and customized product $i$ to the service level of the seller. $c_{t}$ and $c_{e i}$ are the production costs of unit standard product and unit customized product $i \cdot \mu_{i}$ is the share of customized product $i$ in all customized products.

Make $\beta_{t}=\beta_{t} c_{t}, \beta_{e}=\sum_{i=1}^{M} \mu_{i} \beta_{e i} c_{e i}, \gamma_{t}=\sum_{i=1}^{M} \mu_{i} \gamma_{t i} c_{e i}, \gamma_{e}=\gamma_{e} c_{t}$. So (1), (2) turns into

$$
D_{t}=\alpha_{t}-\beta_{t}(1+k)^{2}+\gamma_{t}(1+k)+\delta_{t} l+\tau_{t} s, D_{e}=\alpha_{e}-\beta_{e}(1+k)+\gamma_{e}(1+k)^{2}-\delta_{e} l-\tau_{e} s .
$$

In order to make sense of the problem, suppose $\gamma_{t i}<\beta_{e i}, \gamma_{e}<\beta_{t}, \delta_{t}<\delta_{e}, \tau_{t}>\tau_{e}$, this means that the influence of sales price, order lead time and service level on the product's own demand is greater than the cross-influence [6].At the same time assume that $\gamma_{t i}<\beta_{t}$ and $\gamma_{e}<\beta_{e i}$, this means that the demand for a product is more affected by its own price than by cross-price. Easy to know $\gamma_{i}<\beta_{j}, i, j \in\{t, e\}$.

\section{Profit Function}

(1)Manufacturer's profit function for standard products:

$$
\Phi_{t}=c_{t}(1+k) D_{t}-\left[S_{t} D_{t} / q_{t}+c_{t} D_{t}+q_{t} h_{1} D_{t} / 2 n_{t} P_{t}\right]
$$

It consists of two parts: the profit and cost of standard products per unit time. The cost part includes the preparation cost, production cost and inventory cost of standard products produced by manufacturers. Among them, $S_{t}$ is the preparation cost of each production, and $h_{1}$ is the inventory cost per unit time of the product of the manufacturer.

(2) Manufacturer's profit function of customized products:

$$
\Phi_{e}=c_{e}(1+k) D_{e}-\left[S_{e} D_{e} / q_{e}-\left(h_{1} q_{e} / 2-h_{1} q_{e} D_{e} / 2 P_{e}\right)+c_{e} D_{e}+C_{l}(l) D_{e}\right]
$$

It is composed of two parts, namely, the profit and cost per unit time of the customized products. The cost part includes the preparation cost, inventory cost, production cost and processing and delivery cost of the core products of the customized products produced by the manufacturer. Among them, $S_{e}$ is the preparation cost of each production, $h_{1}$ is the inventory cost per unit time of product of the manufacturer, and $c_{e}=\sum_{i=1}^{M} \mu_{i} c_{e i}$ is the average production cost of customized products.

(3) Seller's profit function:

$$
\Phi_{r}=c_{t}(1+k)^{2} D_{t}-\left[A n_{t} D_{t} / q_{t}+c_{t}(1+k) D_{t}+\left(h_{2} q_{t} / 2-h_{2}\left(n_{t}-1\right) q_{t} D_{t} / 2 n_{t} P_{t}\right)+C_{s}(s)\right]
$$

By the seller unit time sales revenue and cost two parts, the cost part includes the seller's order cost, inventory cost and service cost. Among them, $A$ is the cost of each order, and $h_{2}$ is the inventory cost per unit time of the products sold by the seller. 
(4) The total profit function of the supply chain:

$$
\Phi=\Phi_{t}+\Phi_{e}+\Phi_{r}=K_{t} D_{t}+K_{e} D_{e}-\left(a s^{2}+h_{2} q_{t}+h_{1} q_{e}\right) / 2 .
$$

Where $K_{t}=c_{t} k(2+k)-\left(S_{t}+A n_{t}\right) / q_{t}+q_{t}\left(h_{2}-\left(h_{1}+h_{2}\right) / n_{t}\right) / 2 P_{t}, K_{e}=c_{e} k-S_{e} / q_{e}-c_{L}+q_{e} h_{1} / 2 P_{e}-$ $b(L-l)^{2} / 2$.

The purpose of this paper is to make the optimal decision, which is to determine the markup rate, the service level of the seller, the advance order period of the customized product, the production batch of the manufacturer's standard product and the core product of the customized product, and the order times of the seller in each production cycle, so as to maximize the profit of the supply chain system. Namely

$$
\begin{aligned}
& \max \Phi\left(n_{t}, q_{t}, q_{e}, l, s, k\right) \\
& \text { s.t. } q_{t}>0 ; q_{e}>0 ; n_{t}>0 ; L_{1} \leq l \leq L_{2} ; 0 \leq s \leq 1 ; 0 \leq k \leq k_{0} .
\end{aligned}
$$

\section{Optimal Decision}

Because $\partial^{2} \Phi / \partial n_{t}^{2}=-q_{t}\left(h_{1}+h_{2}\right) D_{t} / P_{t} n_{t}^{3}<0$, so for any given $q_{t}, q_{e}, l, s, k$ there's a unique $n_{t}$ that maximizes $\Phi$ to satisfy $\partial \Phi / \partial n_{t}=D_{t}\left[q_{t}\left(h_{1}+h_{2}\right) / 2 P_{t} n_{t}^{2}-A / q_{t}\right]=0$, namely

$$
n_{t}=q_{t} \sqrt{\left(h_{1}+h_{2}\right) / 2 A P_{t}} \text {. }
$$

From this we can see that for the standard product manufacturer the delivery quantity $q=q_{t} / n_{t}=\sqrt{2 A P_{t} /\left(h_{1}+h_{2}\right)}$ is a constant. Substitute equation (8) into equation (6) to get $K_{t}=c_{t} k(2+k)-S_{t} / q_{t}+h_{2} q_{t} / 2 P_{t}-2 A / q$, the profit function $\Phi$ becomes a function of $q_{t}, q_{e}, l, s$ and $k$. Because $\Phi$ is negative about the Hessian matrix $H_{1}$ of $q_{t}, q_{e}$ (see Appendix 1), so for any given $l, s, k$ has a unique $q_{t}, q_{e}$ to maximize $\Phi$ and satisfy $\partial \Phi / \partial q_{t}=K_{1} D_{t}-h_{2} / 2=0$, $\partial \Phi / \partial q_{e}=K_{2} D_{e}-h_{1} / 2=0$. Namely

$$
q_{t}=\sqrt{2 S_{t} D_{t} P_{t} / h_{2}\left(P_{t}-D_{t}\right)}, q_{e}=\sqrt{2 S_{e} D_{e} P_{e} / h_{1}\left(P_{e}-D_{e}\right)} .
$$

By substituting (8) and (9) into equation (6), the profit function $\Phi$ becomes a function of $l$, $s$ and $k$, and the Hessian matrix of function $\Phi$ is $H_{2}$ (see Appendix 1).If it can proved that $H_{2}$ is negative definite, we can conclude that its optimal solution exists and is unique.

But unfortunately, through a large number of numerical experiments, we find that even for some seemingly reasonable parameters, $\mathrm{H}_{2}$ can not be guaranteed to be negative definite.

The problem must meet the following conditions:

(1) $0 \leq s \leq 1,0 \leq k \leq k_{0}, L_{1} \leq l \leq L_{2}$;

(2) $0 \leq D_{t} \leq P_{t}, 0 \leq D_{e} \leq P_{e}$;

(3) $k(k+2) c_{t}-2 A / q-\sqrt{2 S_{t} h_{2}\left(1 / D_{t}-1 / P_{t}\right)}-a s^{2} / 2 D_{t} \geq 0$,

$$
k c_{e}-\sqrt{2 S_{e} h_{1}\left(1 / D_{e}-1 / P_{e}\right)}-c_{L}-b(L-l)^{2} / 2 \geq 0 \text {. }
$$

Whether traditional products or customized products, if there is no profit, they will not be produced. Therefore, the above conditions (3) must be guaranteed.

Since $\Phi$ is a continuous function of $l, s$ and $k$ in a bounded closed region, its maximum value exists and reaches at the stationary point, that is, the point satisfying

$$
\partial \Phi / \partial l=K_{t} \delta_{t}-K_{e} \delta_{e}+b(L-l) D_{e}=0,
$$




$$
\begin{aligned}
& \partial \Phi / \partial s=K_{t} \tau_{t}-K_{e} \tau_{e}-a s=0, \\
& \partial \Phi / \partial k=2 c_{t}(1+k) D_{t}+K_{t} B_{1}+c_{e} D_{e}+K_{e} B_{2}=0 .
\end{aligned}
$$

or the boundary point in the feasible region.

In summary, the optimal decision of the supply chain exists, which satisfies equations (8), (9), (10),(11) and (12), or at the boundary of $l, s$ and $k$ feasible regions.

\section{Calculation and Analysis}

The program pa_v.m for judging whether the parameters are appropriate, the program co_v.m for judging whether the profit function is concave, and the program phmax.m for finding the optimal solution (see Appendix 2) are compiled by MATLAB. These programs are used for numerical calculation and analysis.

\section{Numerical Example}

Case 1. $M=1, \alpha=[400,600], P=[3000,3000], \beta=[1.2,1], \gamma=[0.4,0.4], a=4, b=2, h=[4,5], \delta=[0.4,0.5]$, $\tau=[0.7,0.3], L=[1,10,14], S=[400,200], k_{0}=0.45, A=20, c=[30,50], c_{L}=1.5$.

By judging and solving, it is concluded that the parameters are appropriate, the profit function $\Phi$ is non-concave, the optimal decision is $l^{*}=10, s^{*}=1, k^{*}=0.45, q_{t}=255, q_{e}=259, n_{t}=2.21$, and the maximum profit is $\Phi^{*}=1.2483 \times 10^{4}$.

Case 2. $M=3, \mu=[0.2,0.3,0.5], \alpha=[15000,9000], P=[18000,18000], k_{0}=0.45, S=[1000,800], A=300$, $\beta=[20,2,2,2], b=0.4, c_{L}=20, L=[2,23,25], c=[350,400,450,500], \gamma=[0.12,0.12,0.12,0.36], \delta=[8,68]$, $a=12000, \tau=[50,20], h=[30,45]$.

By judging and solving, it is concluded that the parameters are appropriate, the profit function $\Phi$ is concave, the optimal decision is $l^{*}=21.19, s^{*}=0.8556, k^{*}=0.3185, q_{t}=420.41, q_{e}=540.6256$, $n_{t}=1.1079$, and the maximum profit is $\Phi^{*}=1330236$.

\section{Comparison with a Single-channel Supply Chain}

Consider the case of two single channels. One is that the demand for customized products will be lost and the demand for standard products will be increased in the traditional situation of selling only through vendors. The other is to sell the standard products in the same way as the customized products only in the case of online sales (see Appendix 3).For the above examples, we obtain the optimal solution and maximum profit for two single channel cases, as shown in Table 1.

Table 1. Optimal decision and maximum profit of single channel supply chain

\begin{tabular}{|c|c|c|c|c|c|c|c|c|}
\hline \multicolumn{2}{|c|}{ Optimal solution and maximum profit } & $k$ & $l$ & $s$ & $n_{t}$ & $q_{t}$ & $q_{e}$ & $\Phi$ \\
\hline \multirow{2}{*}{ Example 11 } & Traditional channels & 0.45 & - & 1 & 2.21 & 255 & - & 10529 \\
\cline { 2 - 9 } & Network channels & 0.45 & 10 & - & - & 295 & 257 & 5396 \\
\hline \multirow{2}{*}{ Example 2 } & Traditional channels & 0.2684 & - & 0.8753 & 1.3 & 493.54 & - & 866899 \\
\cline { 2 - 9 } & Network channels & 0.45 & 18.1438 & - & - & 526.58 & 701.05 & 1417449 \\
\hline
\end{tabular}

It can be seen that the dual-channel supply chain is superior to the traditional channel supply chain, but not necessarily superior to the network channel supply chain. In some environments, the network channel is superior to the dual-channel supply chain, and in other environments, it is inferior to the network channel. Among the three sales modes, the online sales rate is the highest, while the traditional sales rate is the lowest. Sales volume is also the largest online sales, the smallest traditional sales. The lead time of customized products in network sales is less than that in dual-channel sales, while the service level of sellers in dual-channel sales is lower than that in traditional channels. 


\section{Conclusion}

(1) The optimal solution can be reached at the boundary or within the feasible region. The increase of mark-up rate will increase the profit of a single product while reducing the demand for the product, while the increase of service level and the shortening of lead time will increase the demand while increasing the cost. Therefore, it is very important to find a balance among several aspects in practice. The method provided in this paper can help find them.

(2) In the current environment, supply chain should be chosen between two kinds of supply chains: dual-channel supply chain and online sales supply chain. Which one to choose depends on the specific environmental conditions.

(3) Online sales make more demand satisfied. It reduces the selling price of standard products. Although it also increases the selling price of customized products, the sensitivity of customized products to price is generally lower than that of standard products.

(4) Compared with online sales, dual-channel sales extend the lead time of customized products. Compared with traditional sales, dual-channel sales reduces the service level of retailers.

\section{Acknowledgement}

This research was financially supported by the National Natural Science Fund (No. 11471102).

Appendix 1 Expressions of $H_{1}, H_{2}$ and $\Phi$

$$
H_{2}=-\Delta^{T} H_{1}^{-1} \Delta+H_{3} \text {, Among }
$$

$$
H_{1}=\left(-\mathrm{S}_{t} \mathrm{D}_{t} / \mathrm{q}_{t}^{3} \quad 0 \quad ; \quad 0 \quad-\mathrm{S}_{e} \mathrm{D}_{e} / \mathrm{q}_{e}^{3}\right),
$$

$$
\begin{aligned}
& \Delta=\left(\begin{array}{lllllll}
K_{1} \delta_{t} & K_{1} \tau_{t} & K_{1} B_{1} & ; & -K_{2} \delta_{e} & -K_{2} \tau_{e} & K_{2} B_{2}
\end{array}\right), \\
& K_{1}=\partial K_{t} / \partial q_{t}=S_{t} / q_{t}^{2}+h_{2} / 2 P_{t}, K_{2}=\partial K_{e} / \partial q_{e}=S_{e} / q_{e}^{2}+h_{1} / 2 P_{e} . \\
& H_{3}=\left(\begin{array}{ccc}
-2 b(L-l) \delta_{e}-b D_{e} & -b(L-l) \tau_{e} & 2 c_{t}(k+1) \delta_{t}-c_{e} \delta_{e}+b(L-l) B_{2} \\
-b(L-l) \tau_{e} & -a & 2 c_{t}(k+1) \tau_{t}-c_{e} \tau_{e} \\
2 c_{t}(k+1) \delta_{t}-c_{e} \delta_{e}+b(L-l) B_{2} & 2 c_{t}(k+1) \tau_{t}-c_{e} \tau_{e} & z
\end{array}\right), \\
& B_{1}=\partial D_{t} / \partial k=-2 \beta_{t}(k+1)+\gamma_{t}, B_{2}=\partial D_{e} / \partial k=-\beta_{e}+2 \gamma_{e}(k+1), \\
& z=2 c_{t} D_{t}+4 c_{t}(k+1) B_{1}-2 \beta_{t} K_{t}+2 c_{e} B_{2}+2 \gamma_{e} K_{e} . \\
& \Phi(l, s, k) \\
& =\left[k(k+2) c_{t}-2 A / q-\sqrt{2 S_{t} h_{2}\left(1 / D_{t}-1 / P_{t}\right)}\right] D_{t}+\left[k c_{e}-\sqrt{2 S_{e} h_{1}\left(1 / D_{e}-1 / P_{e}\right)}-c_{L}-b(L-l)^{2} / 2\right] D_{e}-a s^{2} / 2 .
\end{aligned}
$$

Appendix 2 Solving optimal solution and several related Matlab programs

1. Program pa_v.m for judging whether the parameters are suitable

$\mathrm{dm} 1=\mathrm{a}(1)+\min \left(-\mathrm{b}(1) *(1+\mathrm{k} 0)^{\wedge} 2+\mathrm{r}(1) *(1+\mathrm{k} 0),-\mathrm{b}(1)+\mathrm{r}(1)\right)+\mathrm{d}(1) * \mathrm{~L}(1)$;

$[\sim, \mathrm{b} 1]=\mathrm{fminbnd}\left(@(\mathrm{k})-\mathrm{b}(2) *(1+\mathrm{k})+\mathrm{r}(2) *(1+\mathrm{k})^{\wedge} 2,0, \mathrm{k} 0\right)$;

$\mathrm{dm} 2=\mathrm{a}(2)+\mathrm{b} 1-\mathrm{d}(2) * \mathrm{~L}(2)-\mathrm{t}(2)$;

$\mathrm{dM} 2=\mathrm{a}(2)-\mathrm{b}(2)+\mathrm{r}(2)+\max (\mathrm{k} 0 *(2 * \mathrm{r}(2)-\mathrm{b}(2)+\mathrm{k} 0 * \mathrm{r}(2)), 0)-\mathrm{d}(2) * \mathrm{~L}(1)$,

[ ,p1]=fminbnd(@(k)b(1)*(1+k)^2-r(1)*(1+k),0,k0);

$\mathrm{dM} 1=\mathrm{a}(1)-\mathrm{p} 1+\mathrm{d}(1) * \mathrm{~L}(2)+\mathrm{t}(1)$; 


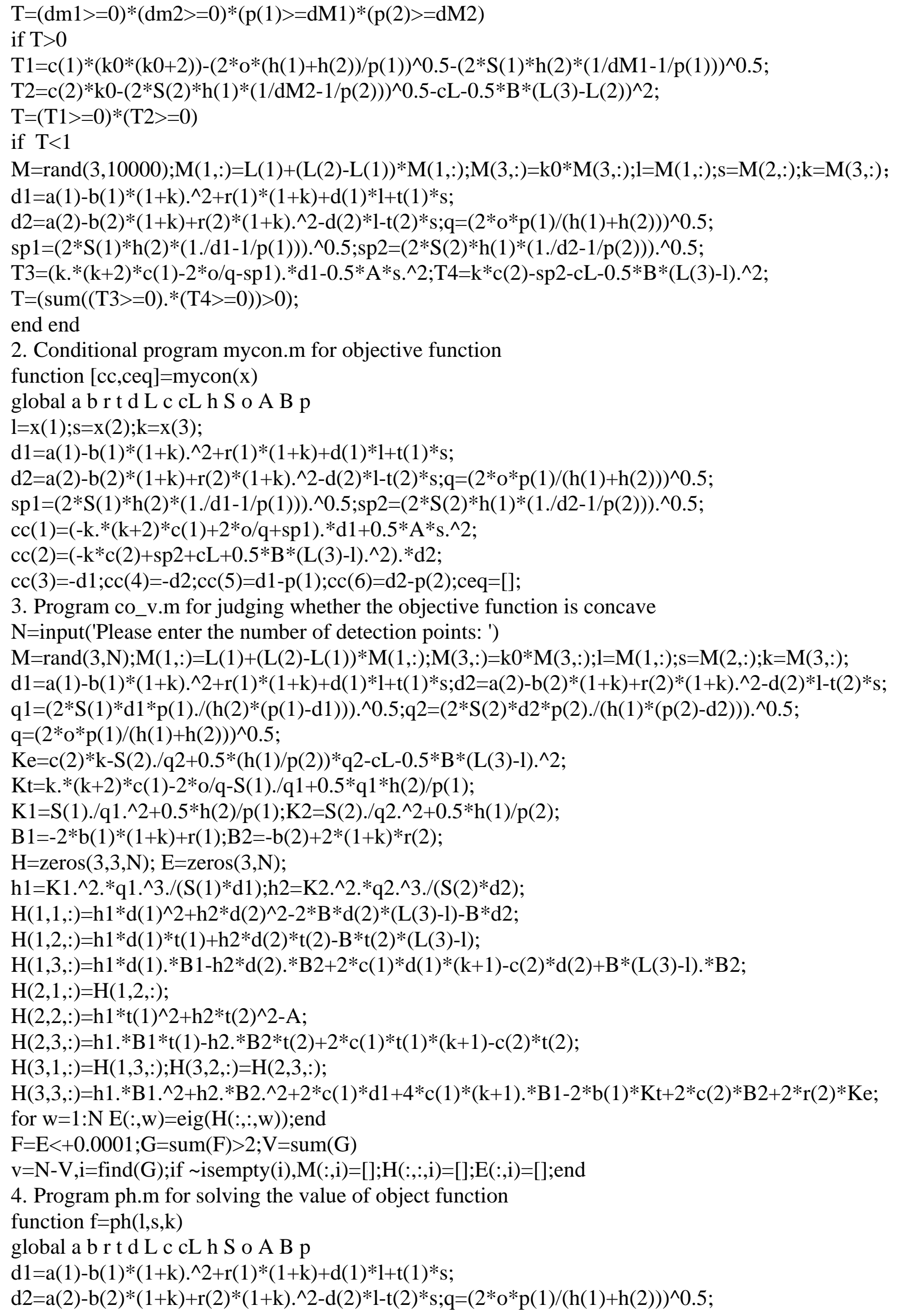


$\mathrm{sp} 1=(2 * \mathrm{~S}(1) * \mathrm{~h}(2) *(1 . / \mathrm{d} 1-1 / \mathrm{p}(1))) . \wedge 0.5 ; \mathrm{sp} 2=(2 * \mathrm{~S}(2) * \mathrm{~h}(1) *(1 . / \mathrm{d} 2-1 / \mathrm{p}(2))) . \wedge 0.5$;

$\mathrm{f}=(\mathrm{k} . *(\mathrm{k}+2) * \mathrm{c}(1)-2 * \mathrm{o} / \mathrm{q}-\mathrm{sp} 1) .{ }^{*} \mathrm{~d} 1+(\mathrm{k} * \mathrm{c}(2)-\mathrm{sp} 2-\mathrm{cL}-0.5 * \mathrm{~B} *(\mathrm{~L}(3)-\mathrm{l}) . \wedge 2) . * \mathrm{~d} 2-0.5 * \mathrm{~A} * \mathrm{~s} . \wedge 2$;

5 . Find the optimal solution of the program phmax.m

$\mathrm{M}=\mathrm{rand}(3,10000) ; \mathrm{M}(1,:)=\mathrm{L}(1)+(\mathrm{L}(2)-\mathrm{L}(1)) * \mathrm{M}(1,:) ; \mathrm{M}(3,:)=\mathrm{k} 0 * \mathrm{M}(3,:) ; \mathrm{l}=\mathrm{M}(1,:) ; \mathrm{s}=\mathrm{M}(2,:) ; \mathrm{k}=\mathrm{M}(3,:) ;$

$\mathrm{d} 1=\mathrm{a}(1)-\mathrm{b}(1) *(1+\mathrm{k}) \cdot \wedge 2+\mathrm{r}(1) *(1+\mathrm{k})+\mathrm{d}(1) * \mathrm{l}+\mathrm{t}(1) * \mathrm{~s}$

$\mathrm{d} 2=\mathrm{a}(2)-\mathrm{b}(2) *(1+\mathrm{k})+\mathrm{r}(2) *(1+\mathrm{k}) . \wedge 2-\mathrm{d}(2) * \mathrm{l}-\mathrm{t}(2) * \mathrm{~s} ; \mathrm{q}=(2 * \mathrm{o} * \mathrm{p}(1) /(\mathrm{h}(1)+\mathrm{h}(2))) \wedge 0.5$;

$\mathrm{sp} 1=(2 * \mathrm{~S}(1) * \mathrm{~h}(2) *(1 . / \mathrm{d} 1-1 / \mathrm{p}(1))) . \wedge 0.5 ; \mathrm{sp} 2=(2 * \mathrm{~S}(2) * \mathrm{~h}(1) *(1 . / \mathrm{d} 2-1 / \mathrm{p}(2))) . \wedge 0.5$;

$\mathrm{T} 3=(\mathrm{k} . *(\mathrm{k}+2) * \mathrm{c}(1)-2 * \mathrm{o} / \mathrm{q}-\mathrm{sp} 1) . * \mathrm{~d} 1-0.5 * \mathrm{~A} * \mathrm{~s} . \wedge 2 ; \mathrm{T} 4=\mathrm{k} * \mathrm{c}(2)-\mathrm{sp} 2-\mathrm{cL}-0.5 * \mathrm{~B} *(\mathrm{~L}(3)-\mathrm{l}) . \wedge 2$;

$\mathrm{T}=(\mathrm{T} 3>=0) . *(\mathrm{~T} 4>=0) . *(\mathrm{~d} 1>=0) . *(\mathrm{~d} 1<=\mathrm{p}(1)) \cdot *(\mathrm{~d} 2>=0) . *(\mathrm{~d} 2<=\mathrm{p}(2))$;

if $\operatorname{sum}(\mathrm{T})>0$

$\mathrm{i}=$ find(1-T);M(:,i)=[];l=M(1,:);s=M(2,:);k=M(3,:);

$\mathrm{y}=\mathrm{ph}(\mathrm{l}, \mathrm{s}, \mathrm{k}) ;[\mathrm{v}, \mathrm{i}]=\max (\mathrm{y})$;

[v,w]=fmincon(@(x)-ph(x(1),x(2),x(3)),M(:,i),[],[],[],[],[L(1),0,0],[L(2),1,k0],@(x)mycon(x));

$\mathrm{W}=-\mathrm{w}$;

else $\mathrm{v}=$ nan*[1;1;1]; $\mathrm{w}=$ nan; end

$\mathrm{l}=\mathrm{v}(1) ; \mathrm{s}=\mathrm{v}(2) ; \mathrm{k}=\mathrm{v}(3)$;

$\mathrm{dt}=\mathrm{a}(1)-\mathrm{b}(1) *(1+\mathrm{k}) \cdot \wedge 2+\mathrm{r}(1) *(1+\mathrm{k})+\mathrm{d}(1) * \mathrm{l}+\mathrm{t}(1) * \mathrm{~s}$;

$\mathrm{de}=\mathrm{a}(2)-\mathrm{b}(2) *(1+\mathrm{k})+\mathrm{r}(2) *(1+\mathrm{k}) \cdot \wedge 2-\mathrm{d}(2) * \mathrm{l}-\mathrm{t}(2) * \mathrm{~s} ; \mathrm{q}=(2 * \mathrm{o} * \mathrm{p}(1) /(\mathrm{h}(1)+\mathrm{h}(2))) \wedge 0.5$;

$\mathrm{qt}=\left(2 * \mathrm{~S}(1) * \mathrm{dt}^{*} \mathrm{p}(1) \cdot /(\mathrm{h}(2) *(\mathrm{p}(1)-\mathrm{dt}))\right) \cdot \wedge 0.5 ; \mathrm{qe}=(2 * \mathrm{~S}(2) * \mathrm{de} * \mathrm{p}(2) \cdot /(\mathrm{h}(1) *(\mathrm{p}(2)-\mathrm{de}))) \cdot \wedge 0.5 ; \mathrm{nt}=\mathrm{qt} / \mathrm{q} ;$

l,s,k,qt,qe,nt,w

Appendix 3 Single channel problem model

1. In the traditional case, it's only through the seller

At this time, the demand for customized products is lost, and the demand for standard products is $D_{t}=\alpha_{t}-\beta_{t}(1+k)^{2}+\gamma_{t}\left(1+k_{0}\right)+\delta_{t} L+\tau_{t} s$, The total channel profit function becomes

$$
\Phi\left(n_{t}, q_{t}, s, k\right)=K_{t} D_{t}-\left(a s^{2}+h_{2} q_{t}\right) / 2 \text {. }
$$

For any given $s, k, \Phi$ is a concave function of $n_{t}$ and $q_{t}$. Therefore, there exists a unique solution $n_{t}=q_{t} \sqrt{\left(h_{1}+h_{2}\right) / 2 A P_{t}}, q_{t}=\sqrt{2 S_{t} D_{t} P_{t} / h_{2}\left(P_{t}-D_{t}\right)}$ that maximizes $\Phi$. Here

$$
\Phi=\left[k(k+2) c_{t}-2 A / q-\sqrt{2 S_{t} h_{2}\left(1 / D_{t}-1 / P_{t}\right)}\right] D_{t}-a s^{2} / 2 .
$$

Condition (1) becomes $0 \leq s \leq 1,0 \leq k \leq k_{0}$, condition (3) becomes

$$
k(k+2) c_{t}-2 A / q-\sqrt{2 S_{t} h_{2}\left(1 / D_{t}-1 / P_{t}\right)}-a s^{2} / 2 D_{t} \geq 0 .
$$

2. E-commerce, that is, sales only through the Internet At this point, the demand for customized products is

$$
D_{e}=\alpha_{e}-\beta_{e}(1+k)+\gamma_{e}(1+k)-\delta_{e} l .
$$

The demand for the standard product is

$$
D_{t}=\alpha_{t}-\beta_{t}(1+k)+\gamma_{t}(1+k)+\delta_{t} l .
$$

The profit function of the manufacturer for standard products becomes

$$
\Phi_{t}=\left[c_{t}(1+k)-S_{t} / q_{t}-c_{t}-c_{L}+q_{t} h_{1} / 2 P_{t}\right] D_{t}-h_{1} q_{t} / 2
$$

The total channel profit function is

$$
\Phi=\left[c_{t} k-S_{t} / q_{t}-c_{L}+q_{t} h_{1} / 2 P_{t}\right] D_{t}+\left[c_{e} k-S_{e} / q_{e}+h_{1} q_{e} / 2 P_{e}-C_{l}(l)\right] D_{e}-h_{1}\left(q_{t}+q_{e}\right) / 2 .
$$


For any given $k, l, \Phi$ is a concave function of $q_{t}$ and $q_{e}$. Therefore, there exists a unique solution $q_{t}=\sqrt{2 S_{t} D_{t} P_{t} / h_{1}\left(P_{t}-D_{t}\right)}, q_{e}=\sqrt{2 S_{e} D_{e} P_{e} / h_{1}\left(P_{e}-D_{e}\right)}$ that maximizes $\Phi$. Here

$$
\Phi=\left[c_{t} k-c_{L}-\sqrt{2 S_{t} h_{1}\left(1 / D_{t}-1 / P_{t}\right)}\right] D_{t}+\left[c_{e} k-\sqrt{2 S_{e} h_{1}\left(1 / D_{e}-1 / P_{e}\right)}-C_{l}(l)\right] D_{e} .
$$

Condition (1) becomes $L_{1} \leq l \leq L_{2}, 0 \leq k \leq k_{0}$, condition (3) becomes

$$
k c_{t}-c_{L}-\sqrt{2 S_{t} h_{1}\left(1 / D_{t}-1 / P_{t}\right)} \geq 0, k c_{e}-\sqrt{2 S_{e} h_{1}\left(1 / D_{e}-1 / P_{e}\right)}-c_{L}-b(L-l)^{2} / 2 \geq 0 .
$$

\section{References}

[1] Tedeschi B. Compressed data; big companies go slowly in devising net strategy. New York Times, 27(2000).

[2] Chiang W K, Chhajed D, and Hess J D.Direct marketing, indirect profits:A strategic analysis of dual-channel supplychain design, J. Management science, 49.1(2003)1-20.

[3] Tsay A A, Agrawal N. Channel conflict and coordination in the e - commerce age, J. Production and operations management, 13.1(2004)93-110.

[4] Hua G, Wang S, Cheng T C E. Price and lead time decisions in dual-channel supply chains, J. European journal of operational research, 205.1(2010)113-126.

[5] Huang S, Yang C, Zhang X. Pricing and production decisions in dual-channel supply chains with demand disruptions, J. Computers \& Industrial Engineering, 62.1(2012)70-83.

[6] Huang S, Yang C, Liu H. Pricing and production decisions in a dual-channel supply chain when production costs are disrupted, J. Economic Modelling, 30(2013)521-538.

[7] Xia N, Rajagopalan S. Standard vs. Custom Products:Variety,Lead Time,and Price Competition, J. Marketing Science, 28.5(2009)887-900.

[8] Dan B, Xu G, Liu C. Pricing policies in a dual-channel supply chain with retail services, J. International Journal of Production Economics, 139.1(2012)312-320.

[9] Xiao T, Choi T M, Cheng T C E. Product variety and channel structure strategy for a retailerStackelberg supply chain,J. European Journal of Operational Research, 233.1(2014)114-124.

[10]Li G, Huang F , Cheng T C E , et al. Competition Between Manufacturer's Online Customization Channel and Conventional Retailer, J. IEEE Transactions on Engineering Management, 62.2(2015)150-157.

[11]Batarfi R, Jaber M Y, Zanoni S. Dual-channel supply chain: A strategy to maximize profit, J. Applied Mathematical Modelling, 40.21-22(2016)9454-9473. 